\title{
Consideraciones económicas sobre Cádiz durante el Trienio Constitucional
}

\author{
JOSE M. a GARCIA LEON
}

Desde que en 1717 Cádiz consiguió ser el único puerto para el comercio de Indias y pasaran a ella los Tribunales de la Casa de Contratación y el Consulado de Sevilla, la ciudad vivió una oleada de prosperidad muy notable. Todavía en los últimos años del siglo XVIII, a pesar de estar abolido el monopolio del comercio americano desde 1778 , se registraron importantes movimientos comerciales que demostraron la vitalidad de la ciudad (1). Así, el Almanaque Mercantil para el año 1795 presentaba en Cádiz 61 corredores de lonja, 86 directores de compañias de seguros, 119 comerciantes navieros y 15 cónsules pertenecientes a otros tantos países extranjeros (2).

Sin embargo, al declinar el siglo XVIII, la ciudad empezó a arrastrar una cierta decadencia que, partiendo de las guerras marítimas de Carlos IV, se complicó, aún más, con la Guerra de la Independencia. Fue, pues, a partir de 1803 cuando la crisis se agudizó de forma definitiva al aparecer los movimientos independentistas en Hispanoamérica (3). Las Cortes de Cádiz, inmersas en su propia tarea, se vieron

(1) "Sólo en el año de 1784 entraron en Cádiz 55 millones de pesos en oro y plata y en el de 1795 fondearon en la bahía 907 barcos con cargas de 28 millones de pesos fuertes". Cfr. Alvaro PICARDO Y GOMEZ, Cádiz en el comercio de la Indias, Cádiz, 1951, pág. 17.

(2) Almanak Mercantil o guĩa de comerciantes para el año 1795, por D.M.C., Madrid B.M.C. (Guía num.1)

(3) Como detalle curioso de hasta qué punto esta doble problemática convulsionó el mundo de las relaciones comerciales, señalemos que en 1808 , un comerciante inglés desde Londres, expresaba su preocupación a un comerciante gaditano por el giro que estaban tomando los acontecimientos en España, "al haberse roto el sistema de gobierno". Asimismo le instaba a que le tuviera informado de todo lo que ocurriera "ya que, nuestros intereses son recíprocos". Cfr. Carta, Cádiz 22 junio 1808. B.G.T., c/3, f/91. 
impotentes ante este cúmulo de hechos adversos. Por si fuera poco, una intransigencia fuera de lugar se resistía a comprender el verdadero significado de estos brotes emancipadores. Pues, al lado de sueños imperialistas, existía el afán de mantener los intereses creados en la Península (4).

Es bien significativo que cuando la Regencia acordó la libertad de comercio con América, dicha medida provocó un verdadero pánico en el seno de la Junta de Cádiz, compuesta en su mayor parte por comerciantes relacionados con las colonias (5). Incluso, ante las presiones recibidas, la Regencia optó por no seguir adelante con este proyecto. Por si fuera poco, el Estado, en vez de ejercer una política más flexible y pragmática, mantuvo un empecinado proteccionismo que forzosamente acabó resultando contraproducente, en su celo por defender a ultranza la economía peninsular (6).

Con un planteamiento así, la burguesía gaditana no tuvo más remedio que buscar una orientación nueva a su política comercial. La solución, poco a poco atisbada, no fue otra que la del liberalismo económico, que forzosamente debía ir acompañado del liberalismo político.

\section{EL LIBERALISMO COMO POSIBLE SOLUCION}

Con la vuelta al poder de Fernando VII, el absolutismo de nuevo se implantó, quedando olvidada y sin vigor la Constitución de 1812. Otra vez volvieron a ejercer su poder las viejas clases dirigentes y a imponerse las formas políticas antiguas, tanto a nivel eclesiástico como

(4) Javier CUENCA ESTEBAN, Comercio y Hacienda en la economía española al final del Antiguo Régimen. Edición e introducción de José FONTANA. Madrid, 1982, pág. 450.

(5) Reflexiones sobre lo ruinoso que infaliblemente seria a la nación española el comercio libre de sus Indias con el Extranjero. Por C.L.S., Cádiz en la oficina de D. Nicolás Gómez de Requena, imprensor del Gobierno 1811. En parecidos términos se expresaba también el Informe dirigido a S.M. por el Consulado y comercio de esta plaza en 24 de julio sobre los perjuicios que se originarian de la concesión del comercio libre de los extranjeros con nuestras Américas. Cádiz, Imprenta Real, año de 1811. Ambos manifiestos son lo suficientemente significativos para que podamos hacernos una idea de hasta qué punto se hacía gala en Cádiz de esa intransigencia, ya apuntada, en las Visperas del desastre colonial que ya se avecinaba. Asimismo, véase también la obra de J. COROLEU, América, historia de su colonización e independencia, t. III, Barcelona, 1895, pâg. 202.

(6) Antonio GARCIA Y BAQUERO, Comercio Colonial y Guerra revolucionarias. Sevilla, 1972, pág. 243. 
civil. No obstante, el gobierno personal del Rey, que tantas esperanzas despertó, fue creando paulatinamente un descontento generalizado. A la consabida cortedad de miras del monarca hubo de añadirse un cúmulo de circunstancias, hasta cierto punto ajenas a él, que difícilmente podían presuponer un éxito en su gestión (7).

A partir de 1818, la crisis se agudizó ante la difícil situación económica y el caótico estado de la Hacienda, a pesar de las acertadas medidas del ministro Martín de Garay. Con ocasión de la estancia de las Infantas María Isabel y María Francisca de Asís en Cádiz, futuras esposas de Fernando VII y de su hermano Carlos, respectivamente, el gobernador, marqués de Casteldorius, aprovechó su discurso de bienvenida para poner de relieve la delicada situación económica de la ciudad, pidiendo urgentemente medidas "para evitar la ruina que amenaza a este desgraciadísimo comercio" (8). Es evidente que una situación así no podía mantenerse por más tiempo. Por ello, la burguesía, ante el caos económico, fue a basar en "las libertades" la solución idónea para sus problemas, dando vía libre, asimismo, a sus afanes de participación en la toma de decisiones políticas frente a la intervención del Estado, fundamentalmente en los asuntos mercantiles. Este factor económico adverso es el que debemos tener muy en cuenta a la hora de buscar una explicación al apoyo dado por las clases burguesas gaditanas a la causa liberal (9).

Al borde de 1820, ya no se podía soportar por más tiempo la fuerte presión fiscal. Militares jóvenes y decididos, unidos a sectores del comercio, muy ligados a la economía colonial, decidieron implantar, de nuevo, la Constitución de 1812. Pues, perdidos los mercados americanos, era preciso liberar al país de todo tipo de ataduras y de explotaciones caducas (10). Sin embargo, la labor legislativa del Trie-

(7) Véase La crisis del Antiguo Régimen, 1808-1893. Barcelona, 1979, pág. 119. de José FONTANA. También ARTOLA GALLEGO, La España de Fernando VIII, t. XXXIII de la Historia de España, dirigida por D. Ramón MENENDEZ PIDAL. Madrid. 1978, pág, 606 .

(8) Cfr. "Arenga con que el Excmo. Sr. Capitán General y Gobernador de esta plaza presidiendo a su Ayuntamiento felicitó a S.M. y A. al desembarcar en este puerto el día 5 de septiembre de 1816". Cádiz, B.C.G., Papeles Varios. 3.15-2-33.

(9) Antonio GARCIA BAQUERO, ob. cit. pág. 243. Por su parte, José FONTANA afirma que "es, por tanto, razonable el que la burguesía española y muy especialmente la gaditana se decantara hacia formas de gobierno de tipo constitucional". Cfr. La Quiebra de la Monarquía Absoluta. Barcelona, 1971, pág. 187.

(10) José FONTANA, Cambio económico y actividad política en la España del siglo XIX. Barcelona, 1973, pág. 50. 
nio se vio impotente ante la situación heredada, agudizada por el foco insurreccional americano, independientemente de que se echara en falta una mayor imaginación por parte de las propias Cortes liberales, como ha puesto de manifiesto Javier Cuenca Esteban (11). Ni los intentos liberalizadores del comercio, ni los deseos de llegar a un armisticio con los rebeldes americanos, ni, mucho menos, las reformas del sistema de aduanas, pudieron detener lo que ya era imparable (12). La autorización del libre comercio con las Islas Filipinas fue otro duro golpe para el comercio gaditano. En virtud de dicha autorización todo buque nacional podía "hacer el comercio directo desde cualquier puerto español de América y Europa a los puertos extranjeros de la India Oriental y la China (13). Aunque las quejas conjuntas del Ayuntamiento, Diputación Provincial y Consulado de Cádiz no se hicieron esperar, poco pudieron hacer para revocar este decreto liberalizador (14).

En 1821, se dejó decir públicamente en las Cortes que el pueblo español "nadaba en la miseria", echándose de menos "los metales preciosos que han salido para el extranjero y que no han sido reemplazados por las flotas que venían antes de nuestras Américas" (15). A pesar de ello proliferaron las publicaciones liberales en las que achacaban todos los males del país, de forma terminante, a los seis años absolutistas inmediatamente precedentes (16).

Hemos de remitirnos, pues, al problema americano para entender mejor la crisis profunda del comercio gaditano, de la que ya no se repuso jamás (17).

(11) Ob. cit. pág. 444.

(12) Con el nuevo sistema aduanero, Cádiz quedó como depósito de primera clase, estando habilitada para el comercio extranjero de importación y exportación y para el de América. Sistema General de Aduanas de la Monarquía española en ambos bemisferios, aprobado por las Cortes Ordinarias del año 1820. Madrid, 1820. Imprenta Real de las Cortes. Por Diego García Campoy, pág. 249.

(13) Cfr. "Decreto XVIII de 9 de noviembre de 1820 sobre libre comercio con las Islas Filipinas". C.D.O.G. de la Primera Legislatura. Cortes Ordinarias, 1820-1821, t. VI. Madrid, Imprenta Nacional, 1821.

(14) Diario de las Actas y Discusiones de las Cortes, Legislatura de los años 1820-1821, t.XX, año 1821, "Sesión del día 3 de junio de 1821".

(15) Cfr. Diario de Cortes, "Sesión del día 12 de junio de 1821", t. XXI, pág. 37.

(16) Un buen ejemplo de ello lo constituye el Resumen Histórico de la Hacienda Pública de España. Cotejo de los Planes formados y Observaciones generales. Por el Dr.A.A, Zaragoza. Imprenta de la calle del Coso. Año de 1822.

(17) Por ello, difícilmente podemos dar crédito a MOREAU DE JONNES cuando escribe acerca "de la poca influencia que han tenido los grandes acontecimientos de la emancipación de las colonias de España sobre el destino de la Península y sobre su mercado" Cfr. Estadística de España (Territorio, población...) traducida por D. Pascual Madoz e Ibáñez. Barcelona, 1835, pág. 213. 


\section{EL IMPACTO DE LA INDEPENDENCIA DE LAS COLONIAS AMERICANAS EN CADIZ}

La independencia de las colonias americanas supuso para España una pérdida vital para su sistema económico, y para Cádiz su ruina, ya que prácticamente la ciudad había vivido del comercio con América. Mucho se ha generalizado acerca de la poca incidencia que tuvo en la opinión pública esta pérdida, pues sólo una tibia indignación, cuando no indiferencia, presidieron a nivel de dicha opinión pública el suceso independentista (18).

No obstante estas consideraciones, es posible que sean válidas para lo que podríamos calificar de "opinión nacional" pues, por lo que a Cádiz respecta, el impacto en la ciudad adquirió unas dimensiones muy distintas a las del resto de España. En esos momentos, no deja de ser bien significativa una carta pública de un comerciante gaditano, donde se expresaba que la ciudad acababa de perder "todo su lustre, toda su opulencia..." y abogaba en una postura realista, exenta ya de pasadas ínfulas imperialistas, por "una unión, una igualdad bien combinada, sin monopolios ni privilegios exclusivos..." (19).

Bien es verdad que, hasta el último momento, se esperó en conseguir un acuerdo. Es innegable la ingenuidad de nuestros gobernantes en 1820, pues creyeron que reimplantada la Constitución el problema colonial se solucionaría como si sólo se tratara de llegar al liberalismo. Hasta tal punto esto fue así que, por una real orden de 31 de Mayo, se dispuso que una vez jurada la Constitución cesasen las hostilidades. Pero, como señala Jerónimo Bécker, "la soberanía del conflicto hispanoamericano no estribaba en un mero cambio de régimen, sino en un cambio de soberanía" (20). Incluso, una vez admitida ya la

(18) Aun así, como dato curioso, reproducimos seguidamente estas palabras de Martínez de la Rosa, no suficientemente divulgadas, que reflejan su preocupante comprensión del problema: "Conviene reflexionar sobre uno de los acontecimientos más asombrosos de la edad presente: la destrucción del antiguo sistema colonial y la emancipación de las colonias, acontecimientos de tanta magnitud, que no alcanzamos a comprenderle". Cfr. El Espiritu del Siglo. Cap. XVIII, lib. VIII, t. VI. Madrid, 1843, pág. 294.

(19) Cfr. "Algunas reflexiones sobre la carta del americano español Don Enrique Somozar, en la Gaceta Patriótica, num. 26". Por Mier, del comercio de Cádiz, 26 de abril de 1820 (artículo remitido interpolado en la Colección del Diario Mercantil de Cádiz, nums. 1.375 y 1.376 ).

(20) Cfr. La Independencia de América (su reconocimiento por España). Madrid, 1922, pág. 68. Por su parte, Melchor FERNANDEZ ALMAGRO, redundando en lo anteriormente expuesto, afirma que si sólo se hubiera tratado de un cambio de siste- 
pérdida de las colonias, se pensó en un intento de aproximación en la forma de una posible confederación, sobre la que una pluma crítica como la de Monseñor Pradt, Arzobispo de Malinas, se mostró pesimista desde el primer momento (21). Ante este proyecto, hubo en Cádiz quien temió que esta posibilidad supusiera una vuelta "a los tiempos de la botija y de enriquecer sin trabajar". Y más de una queja se dejó oír ante el tradicional poco tacto de nuestros diplomáticos a la hora de establecer acuerdos, "prueba es las ventajas que por ellos han obtenido los extranjeros en perjuicio nuestro" (22).

1820 fue, pues, una año de relativas esperanzas, que pronto se desvanecieron en unas conversaciones que demostraron ser ficticias y que culminaron negativamente para la Metrópoli con la independencia de Perú ( 28 de julio) y Méjico ( 28 de septiembre). Ante un panorama así, las quiebras de establecimientos gaditanos se sucedieron en cadena: 19 en 1820, 15 en 1821, 17 en 1822 y 5 en 1823, según los estudios realizados por Antonio García Baquero (23). Asimismo, según las fuentes consultadas, las exportaciones de Cádiz siguieron una línea descendente entre 1820 y 1823 :

\begin{tabular}{lrrr} 
& Libras & Quintales & Arrobas \\
\hline 1820 & 1.910 .132 & 9.631 & $1.230(24)$ \\
1821 & 1.812 .173 & 10.509 & $6.676(25)$ \\
1822 & 1.352 .529 & 2.012 & $240(26)$ \\
1823 & 867.445 & 416 & $6.034(27)$
\end{tabular}

ma de gobierno "el conflicto no habría sido mucho aliento y se hubiera resuelto sin grandes dificultades a favor del Gobierno Liberal". Cfr. La Emancipación de América y su reflejo en la conciencia española. I.E.P. Madrid, 1944, pág. 52.

(21) De la Revolución actual de España y de sus consecuencias. Valencia, 1820, pág. 216. Con especial énfasis $M$. de PRADT denuncia la política colonial española, a la que califica de "catastrófica, anacrónica, equivocada y vacilante", lo cual traía consigo el que "España fuera una pieza codiciada por las naciones potentes y ambiciosas como Inglaterra", Cfr. AYMES, Jean René. "El Abate de Pradt y España" (segunda parte, los años 1814-1823), Revista Trienio num. 7. Madrid, 1986, pág. 20.

(22) Cfr. "Carta de un comerciante gaditano a la Sociedad Económica" (interpolada en la colección del D.M.C. nums. 1.458 y 1.459).

(23) Ob. cit. págs. 239, 240 y 241.

(24) D.M.C. nums. 1.441, 1.445, 1.469, 1.497, 1.511, 1.525, 1.532, 1.551, 1.562, 1.586 y 1.600 .

(25) D.M.C. nums. 1.673, 1.697, 1.708, 1.743, 1.771, 1.809, 1.834, 1.872, 1.914, $1.940,1.971$ y 1.999

(26) D.M.C. nums. 2.034, 2.045, 2.108, 2.143, 2.073, 2.178, 2.201, 2.243, 2.301, 2.336 y 2.350 .

(27) D.M.C. nums. 2.404, 2.427, 2.450, 2.490, 2.518, 2.536, 2.570 y 2.594. 
A fines de 1821, el Diario Mercantil de Cádiz insertaba estas líneas relativas al estado del comercio de la ciudad:

"Sigue en la misma situación miserable de que se dió noticia anteriormente. Camina rápidamente a su ruina, y todo indica un porvernir tan desastroso como cierto. Es evidente la pérdida de esta hermosa ciudad si su gobierno no la socorre con poderosa mano, venciendo todos los obstáculos que se oponen a su fomento" (28).

Pocos meses después, en febrero de 1822, los comerciantes gaditanos hacían ver a las Cortes su preocupación por la ruptura del comercio con las nuevas repúblicas independientes, agravada por no respetarse las propiedades de los peninsulares. Como posible solución se apuntaba hacia el respeto de esas propiedades, con el compromiso de admitirse en la Península las futuras expediciones provenientes de América con los mismos derechos que antes de la independencia. De esta forma, según los comerciantes gaditanos "se daría el primer paso positivo para la conservación o restablecimiento de unas conexiones que pudieran ser vehículo feliz que algún día estrechase con lazos de justicia y beneficencia a todos los hijos de los dos hemisferios españoles" (29).

\section{EL CONTRABANDO}

Una de las consecuencias inevitables de la excesiva política proteccionista del gobierno fue la proliferación del contrabando, que acarreó el consiguiente perjuicio a la economía nacional y el lucro de quienes lo ejercieron.

Ya en la segunda mitad del siglo XVIII fueron numerosos los casos de contrabando repartidos por la costa gaditana, algunos de ellos de muy alto nivel (30). Ahora, en el Trienio, en unos momentos de clara crisis económica, se potenció esta práctica, no sólo en Cádiz, sino también en algunas zonas de su provincia, preferentemente el Campo de Gibraltar, muy propicio para este delito, por su cercanía a la plaza británica y por sus latifundios muy poco explotados, con una población desocupada casi todo el año, siendo notable el hecho de que esta práctica del contrabando pasaba de padres a hijos (31).

(28) D.M.C. nums. 1.251, 2.006 y 2.368.

(29) Cfr. D.M.C. nums 1.904, 19 octubre 1821.

(30) Cfr. "Representación dirigida al Congreso Nacional por varios individuos del comercio de Cádiz", D.M.C. num. 2.013, 8 febrero 1822.

(31) Amalia GOMEZ GOMEZ señala que el contrabando "era difícil de prevenir o evitar no ya sólo por la estrecha relación entre comerciantes y contrabandistas sino, sobre todo, por la ineficacia e incluso participación del funcionariado en estas 
Cádiz, puerto de importancia que acusaba ya la decadencia que hemos apuntado, era lugar fácil para el contrabando, siendo considerable los testimonios relativos a este hecho, como seguidamente iremos viendo. No deja de ser muy significativo que, en la Descripción de Cádiz de 1820, se mencionara, entre otras debilidades de los gaditanos, la de ser "amantes de la ociosidad y dados al contrabando" (32). Por lo que se desprende de las fuentes consultadas, era notoria la impunidad con que se vendían públicamente los productos de contrabando ante la mirada condescendiente de los agentes de la ley. No pueden ser más contundentes las quejas de los hombres de la policía y la Milicia Nacional al considerarse "en situación embarazosa...al ver salir en libertad a individuos que pocos días antes han salido arrestados in fraganti por varios delitos" (33). Alexander Shidell nos cuenta que al llegar, por estos años, al control de la aduana logró salir con la gratificación al funcionario de turno, no pasada a escondidas, sino "entregada a la vista de todo el mundo" (34).

En esto inicios del Trienio, ya el problema empezaba a preocupar seriamente a las autoridades locales, que denunciaban "la multitud de contrabando... en escandaloso, criminal y absoluto abandono" (35). No solamente era el puerto el lugar exclusivo, sino que se utilizaban otros sitios más "sofisticados", como los conductos que desembocaban al mar por la Caleta (36). Era, por tanto, del dominio público la connivencia de los contrabandistas con los funcionarios de Aduana. Como consecuencia de ello, el Ayuntamiento publicó un Manifiesto en el que se anunciaban ejemplares castigos, no especificados, contra los contrabandistas, a la vez que se volvía a denunciar "el escandaloso y

prácticas ilegales". Cfr. "Nota sobre el contrabando gaditano a fines del siglo XVIII". En la Bungesía mercantil gaditana, pág. 239. Asimismo, de Rafael SANCHEZ MANTERO, véase La decadencia comercial de Cádiz y el síndrome de Gibraltar, I Jornada de Andalucía y América, Sevilla 1982. Finalmente, de Georges, HILLS, El Peñón de la discordia. Historia de Gibraltar. Madrid, 1979, pág. 447.

(32) Descripción, ob. cit. pág. 19. También Moreau de Jonnes, resalta la importancia de este contrabando, Ob. cit. pág. 244. Y Richard Ford, en sus impresiones recogidas por sus viajes por el Sur de España nos dejó escrito que "no hay delito que sea castigado más terriblemente en España que el contrabando de tabaco". Cfr. Cosas de España. Madrid, 1974, pág. 367.

(33) D.M.C. m. 1790 (1 Julio 1821)

(34) Cfr. "A Year in Spain, by a young American", Londres 1831, Vol. II. En la Andalucia de los libros de viajes del siglo XIX. (Antología) de Mànuel BERNAL RODRIGUEZ. Sevilla, 1985, pág. 79.

(35) Cfr. A. C.M.C. or., num. 100, 14 octubre 1820, pág. 8.

(36) Cfr. Ibídem, pág. 10. 
detestable arrojo con que muchos de sus habitantes, abandonando sus talleres, el ejercicio de sus profesiones y tranquilidad civil y doméstica de su familia, se dedican al comercio clandestino, introduciendo contrabando de todas las especies" (37).

No faltaron las voces que repetidamente pedian una solución al problema. Así, en el informe que el Intendente de la ciudad envío al Tribunal del Consulado, hacía notar que era "demasiado escandaloso lo que se está haciendo de algún tiempo a esta parte". También incidía en la corruptibilidad de los delitos, pues la opinión general designaba "las casas y las personas empleadas en un tráfico tan funesto" (38). De especial significación fue la denuncia de Clararrosa, uno de los hombres que más influyeron en la opinión pública. Es obvio su reconocimiento del contrabando, al que consideraba extendido de "modo horroroso por todos los puntos de la nación". Aprovechando su denuncia para arremeter contra el sistema liberal presente, en el que ve una revolución frustrada, con una serie de individuos interesados en mantener antiguos privilegios, especialmente los funcionarios de Hacienda y Aduanas, a los que acusaba de corrupción y de conspiración permanente contra el sistema (39). Tampoco faltaron, en este tipo de denuncias, quienes abogaban por las excelencias de las manufacturas españolas frente a las extranjeras, en un estéril intento por reprimir el contrabando. En consecuencia, pedían una concienciación pública ante "la fatal preferencia que damos a los productos extranjeros en siendo inferiores a los nuestros" (40).

Una cuestión que fue motivo de preocupación para los comerciantes gaditanos fue el hecho de que, a partir de 1820, se había ido acumulando en Cádiz una serie de géneros que con la ley nueva de aranceles de 1821 encontraban prohibida su venta. El problema urgía una pronta solución, dado que estos artículos, destinados a ser consu-

(37) Cfr. "Manifiesto. Don José Vicente de Durana y Don Pedro de la Puente, alcaldes constitucionales de esta ciudad, Cádiz 22 de agosto 1820", D.M.C., num. 1.482.

(38) En su denuncia, insistía "en la averiguación de los que debiendo impedirlo contribuyen tal vez a protegerlo", Cfr. D.M.C., num. 1.796, 7 julio 1821.

(39) "Las cargas que hicieron que el despotismo se hundiese y que la nación haya venido al estado lamentable en que se halla, aún existen todavía". Cfr. "Hablemos de par en par. Reflexiones del ciudadano Clararrosa sobre el plan de Hacienda Nacional y diferentes otros ramos de administración pública". Interpolado en la Colección del D.M.C. nums. 1.801-1.802, 13 de julio 1821.

(40) "La manufactura española más bien acabada apenas encuentra comprador si no se supone fabricada en el extranjero". Cfr. "Sobre el Contrabando". D.M.C., num. 2.309, 30 noviembre 1822 . 
midos en las provincias ultramarinas, donde a su vez también estaban prohibidos, pasaban a Gibraltar y de ahí a América, o se introducían clandestinamente en el resto de la Península (41). Como consecuencia de ello, las Cortes no tuvieron otra opción que la de permitir el despacho para Ultramar de todos los géneros existentes, no sólo ya en el depósito de Cádiz, sino en los de los restantes puertos peninsulares, y que estaban permitidos ante la entrada en vigor de los nuevos aranceles (42). Así pues, la petición de la abolición de ramos estancos, la necesidad de una reforma más eficaz del régimen de aduanas, la fuerte competitividad de las manufacturas extranjeras frente a las nacionales y, finalmente, los problemas derivados del contrabando, dieron, todos ellos, como resultado una asfixiante situación económica. Se hacía preciso, pues, liberalizar una serie de impuestos y trabas administrativas, sobre todo con los productos americanos.

En una Memoria enviada por los comerciantes gaditanos a las Cortes en 1820, se hacía la siguiente reflexión, a modo de denuncia:

"Cómo puede ser justo que una fanega de cacao de Guayaquil que vale 4 pesos al tiempo de su embarque haya de pagar a su entrada en la Península más de 7 pesos de derechos y el de Caracas más de 11, con lo cual no solo se facilita el contrabando, sino que se aminora el consumo y se destruye el cultivo de tan precioso fruto?" (43).

Como posible solución, pronto surgieron las diversas peticiones tendentes a alcanzar un preciado objetivo, la consecución del puerto franco (44).

\section{EL PUERTO FRANCO: UNA PETICION FRUSTRADA}

La primera petición del puerto franco gaditano se debe al conde de Maule, quien vio en la consecución de dicha franquicia la solución más idónea para aliviar la progresiva decadencia que Cádiz empezó a

(41) Cfr. "Sesión de Cortes, 17 diciembre 1821, D.A.D. de las Cortes Extraordinarias, año 1821, Tomo VI, pág. 6.

(42) Sesión de Cortes... ob. cit. pág. 7.

(43) Cfr. Memoria sobre los males que sufre el Comercio español y medios de repararlos. Escrita y dirigida a las Cortes por una Comisión del Comercio de Cádiz, Año de 1820 , pág. 26.

(44) Argumenta dicha memoria que "ninguna nación tiene un Cádiz que se ve como destinado por la naturaleza para ser almacén general del comercio del mundo". Como consecuencia de ello sugiere que "Cádiz rivalizando el comercio de Gibraltar y Portugal, concurrirá de un momento evidente y positivo a la extinción del contrabando". Ibídem, pág. 195. 
mostrar desde que se inició el siglo XIX. Incluso llegó a diseñar algunas características que el nuevo puerto debería presentar (45). Sin embargo, tal proyecto no se tuvo en cuenta y, aunque se volvió insistentemente a pedir de nuevo el puerto franco al acabar la Guerra de la Independencia, tampoco se logró ver materializada dicha petición (46).

En 1820, pues, como hemos tenido ocasión de comprobar en la Memoria citada anteriormente, se recurrió otra vez a solicitar la ansiada franquicia, como auténtica tabla de salvación para los males de la ciudad, señalándose que "no sería un privilegio, sino elegir un punto ideal (47)". Por ello, el Consulado, conjuntamente envió a las Cortes en 1821 sus quejas en las que se abogaba por el puerto franco. Fue en 1822, año en el que las exportaciones decayeron ostensiblemente y la independencia americana pareció un hecho consumado, cuando se hicieron más insistentes las peticiones del puerto franco. Así, en la Memoria del comercio se puede leer que "sólo podrá reanimarse si afortunadamente las Cortes conveniendo con las pretensiones que con tanta instancia se le ha hecho, decretan que esta plaza sea puerto franco de libre comercio; de otro modo es evidentísima su ruina" (48).

El periódico madrileño "El amigo del Comercio" insertó un artículo donde muy enfáticamente pedía también la deseada franquicia (49). Poco después la Diputación Provincial, en solitario, volvió a insistir, teniendo siempre presente el problema americano, por lo que no descartaba todavía que el nuevo puerto serviría para atraer por medio de la franquicia los frutos de uno y otro hemisferio (50). Y finalmente, el Consulado, en el caso de que se consiguiera el puerto franco, se daba un plazo de dos años para que "experimentase la España toda sus benéficos efectos" (51).

Sin embargo, y a pesar de todas estas reiteradas peticiones, lo cierto es que hubo que esperar hasta el real decreto de 21 de febrero de 1829 para que Cádiz, aunque por poco tiempo, viera colmado su deseo, cuya consecución se había ido convirtiendo en una meta obse-

(45) Viaje de España, Francia e Italia, tomo XIII (que trata de Cádiz y su comercio). Cádiz, 1813, pág. 403.

(46) Antonio GARCI BAQUERO, ob. cit. pág. 249.

(47) Cfr. Memoria, ob. cit. pág. 196. Véase también la Representación dirigida a las Cortes por la Diputación Provincial, Ayuntamiento y Consulado de Cádiz sobre diferentes objetos del comercio nacional. Cádiz, 1821.

(48) Cfr. A.M.C., Carp. 1.822, expd. 243.

(49) D.M.C. num. 2.034, 1 marzo 1822

(50) D.M.C. num. 2.055, 22 marzo.

(51) Cfr. D.M.C. num. 2.067, 3 abril 1822. 
siva. Mientras, los años que mediaron desde 1823 hasta esa fecha afortunada, sólo pudieron contemplar "el ruinoso estado mercantil" de una ciudad que caminaba "presurosamente hacia su total exterminio" (52).

Por último, la situación que contemplamos en la recta final del Trienio se complicó alarmantemente con el boicot de las potencias europeas al régimen liberal español, teniendo que soportar Cádiz los efectos de una economía de sitio, que vino a rematar definitivamente tan desdichada caída. A todo este cúmulo de problemas ecónomicos hay que añadir la especial situación que se vivió en la ciudad al tener que soportar un nuevo asedio. El estado de la Hacienda era caótico y ya, desde 1823, casi declarada de forma oficiosa la guerra a Francia, el Gobierno español decidió recurrir al empréstito extranjero como forma de salir de la complicada situación económica.

Al acabar la aventura del Trienio, corta e intensa, Cádiz aparece como una ciudad maltrecha y castigada por los acontecimientos adversos que le tocó vivir, desde el impacto de las colonias americanas independientes, hasta el asedio final de los últimos meses previos a la caída del liberalismo. Por ello, muy acertadamente, el varias veces citado García Baquero, ha escrito, con cierta nostalgia contenida, que "de aquel gran emporio comercial que fue Cádiz en el siglo ilustrado no quedaban para sus comerciantes más que ruinas y recuerdos por los que lamentarse" (53).

(52) Cfr. D.M.C. num. 2.543, 22 junio 1823.

(53) Ob. cit. pág. 254. 